\title{
Evoked potentials and cerebral blood flow in solvent induced psycho-organic syndrome
}

\author{
D Deschamps, R Garnier, F Lille, Y Tran Dinh, L Bertaux, A Reygagne, S Dally
}

\begin{abstract}
Epidemiological studies have provided evidence that neuropsychiatric symptoms are induced by long term exposure to solvents; individual diagnosis with psychometric tests, however, is not always possible (for example, when the patient has linguistic difficulties). Therefore evoked potentials and cerebral blood flow were studied in 50 patients occupationally exposed to solvents who were referred to our department and for whom a solvent induced psycho-organic syndrome was suspected. Degree of exposure was evaluated by its duration (mean 13.9, range 1 to 37 years) and its intensity (from an interview). At the group level, P22 and N35 latencies and amplitude N20-P22 of somatosensory evoked potentials were higher in cases than in controls $(p<0.05)$, whereas there was no difference for brainstem and visual evoked potentials, nor for hemispheric cerebral blood flow (but a higher distribution in the left occipital region was seen in patients, $p<0.05$ ). Some parameters were linked to degree of exposure (amplitude N20-P22 of somatosensory evoked potentials, interpeak latency I-V of brainstem evoked potentials, distribution of cerebral blood flow in the internal frontal left region). At the individual level, these examinations were not of diagnostic value because sensitivity was low.
\end{abstract}

(British fournal of Industrial Medicine 1993;50:325-330)

Service de médecine interne et de toxicologie clinique, Hôpital Fernand Widal, 75475 Paris cedex 10, France

D Deschamps, L Bertaux, S Dally

Centre anti-poisons, Hôpital Fernand Widal, 75475

Paris cedex 10, France

R Garnier, A Reygagne

Centre National de la Recherche Scientifique UA 385, CHU Pitié Salpétrière, 75013 Paris, France F Lille

Service d'explorations fonctionnelles du système nerveux, Hôpital Lariboisière, 75010 Paris, France Y Tran Dinh
Neurobehavioural effects of occupational exposure to organic solvents have given rise to numerous studies in industry. ${ }^{1}$ Although acceptable exposure concentrations have not yet been established, it is admitted that exposure to high concentrations can cause lasting alterations in cognitive function. ${ }^{2}$ As neurobehavioural impairments are not specific, it is difficult to clinically diagnose a solvent induced psycho-organic syndrome in a patient with subjective symptoms, and for whom being awarded compensation may be a consideration.

Many studies have been conducted with psychometric tests. Nevertheless, their results do not confirm the existence of solvent induced psychoorganic syndrome: they are not abnormal at the early stage of the disease, when recovery after removal of exposure occurs in most cases ${ }^{3}$; so it could be judicious to complement them with research of objective neurological impairments by imaging or electrophysiological methods. Evoked potentials (projections of the action potentials on the cortex) and cerebral blood flows (reflecting cerebral metabolism ${ }^{4}$ ) can be perturbed in toxic central neuropathies (for example, from alcohol ${ }^{56}$ ) and could be of good diagnostic value in diseases with subjective symptomatology for which the organic cause is difficult to ascertain-for example, migraine $^{7}$ and perhaps developmental learning disabilities in children. ${ }^{8}$

The aims of this study were to compare with controls the measurements of evoked potentials and of cerebral blood flow in 50 patients who were referred to our department and for whom solvent induced psycho-organic syndrome had been suggested, to search for a link between these results and the degree of exposure, and to evaluate their diagnostic interest by comparing them with the results of psychometric tests.

Methods

SUBJECTS

Cases

The study population consisted of subjects occupationally exposed for more than one year to organic solvents who were referred to our department between 1984 and 1990 and for whom a psychoorganic syndrome was suspected, based on an 
interview. This was because of the degree of exposure or because the reason for consultation was an evocative symptom (fatigue, memory impairment, difficulties in concentration, irritability, sleep disorders, headache). Ninety two persons consulted us. Thirty five were not included because of alcohol consumption $^{569}$ (from either interview, reporting consumption of more than $1 \mathrm{~g} / \mathrm{kg}$ body weight a day, or enhancement of activity of $\gamma$-glutamyltransferase in serum, or increased mean corpuscular volume of red blood cells), or other potential confounding factors. ${ }^{10-20}$ Moreover, for reasons of contingency, seven persons did not undergo measurements of either cerebral blood flow or evoked potentials and were not included. Fifty patients, mean age 40.6 (SD 9.5) years were finally studied. Among these, 13 persons were not included for psychometric tests, because of psychiatric disease or use of psychotropic drugs. Ten patients were painters. Solvents were mostly (44 times out of 50 ) mixtures.

The degree of exposure was measured in two ways. Duration of exposure was 13.9 (SD 10) years. Intensity was designated as mild or severe by four physicians who classified the patients, based on an interview about the workplace, independently and without knowledge of the results of examinations, into (1) severely exposed (probably near or beyond the threshold limit value for at least one solvent) and (2) mildly exposed. In cases of disagreement the class of exposure assigned was the weakest; 32 persons were severely exposed and 18 mildly exposed. Table 1 summarises the characteristics of patients and controls.

\section{Controls}

For evoked potentials, 40 persons of the same age as the cases and without the mentioned confounding factors were included.

For cerebral blood flows, controls were recruited, with the same criteria from the staff of the department. Eighteen controls underwent measurement of cerebral blood flow by tomography, 28 cerebral blood flow with conventional stationary probes.

For psychometric tests, results were compared with those of age adjusted reference tables.

\section{NEUROLOGICAL EXAMINATIONS \\ Neuropsychological tests}

Thirty seven of the 50 subjects underwent the neuropsychological tests summarised in table 2 . These tests covered a wide range of higher central nervous system functions, especially the ones that are most sensitive to deterioration. ${ }^{21-23}$ Because there was no control group, special importance was attached to the vocabulary test: it gives an efficiency level particularly resistant both to mental deterioration ${ }^{24}$
Table 1 Characteristics of cases and controls

\begin{tabular}{lll} 
& Controls & Cases \\
\hline Evoked potentials: & & \\
Number & 40 & 50 \\
Age (y (range)) & $39 \cdot 5(22-59)$ & $40 \cdot 6(24-56)$ \\
Exposure duration (y (range)) & & $13 \cdot 9(1-37)$ \\
Exposure intensity & & High : 32 \\
& & Low: 18 \\
Tomographic cerebral blood flow: & 18 & \\
Number & $35 \cdot 4(21-61)$ & $249 \cdot 1(24-55)$ \\
Age (y (range)) & & $12 \cdot 3(1-36)$ \\
Exposure duration (y (range)) & & High : 14 \\
Exposure intensity & & Low: 10 \\
& & \\
Cerebral blood flow in grey matter: & 28 & 26 \\
Number & $31 \cdot 0(26-45)$ & $41 \cdot 9(24-56)$ \\
Age (y (range)) & & $15 \cdot 3(1-37)$ \\
Exposure duration (y (range)) & & High: 18 \\
Exposure intensity & & Low: 8 \\
\hline
\end{tabular}

and to exposure to neurotoxic agents; so the result reflects the intellectual capacity before the intoxication, and can be compared with the other neuropsychological tests presumed to be affected by exposure to solvents.

\section{Evoked potentials 9}

Somatosensory evoked potentials (SEPS) - In this study we focused our interest on the central parameters of those potentials - that is, on cortical components of the upper limb potentials. Peak latencies were measured at the parietal level (N20, P22, N35), and peak to peak amplitude from N20-P22 was calculated. All the latencies were adjusted to $170 \mathrm{~cm}$ constant size.

Visual evoked potentials (VEPs) - Pattern reversal evoked VEPs were recorded from a central occipital electrode referred to ear lobes. Measurements were made for peak latencies P100 and peak to peak amplitudes $\mathrm{P} 100-\mathrm{N} 140$, and the presence or absence of a W shape of the P100 was noted.

Table 2 Neuropsychological test battery

\begin{tabular}{|c|c|c|}
\hline $\begin{array}{l}\text { Principal function } \\
\text { tested }\end{array}$ & Test method & $\begin{array}{l}\text { Other function(s) } \\
\text { measured with } \\
\text { the test }\end{array}$ \\
\hline $\begin{array}{l}\text { Intellectual functions: } \\
\text { Verbal } \\
\text { Visuospatial }\end{array}$ & $\begin{array}{l}\text { Vocabulary } \\
\text { Similitudes } \\
\text { Cubes } \\
\text { Digit symbol }\end{array}$ & $\begin{array}{l}\text { Verbal ability } \\
\text { Verbal abstraction } \\
\text { Visuoconstructive } \\
\text { ability } \\
\text { Concentration } \\
\text { Shifting ability } \\
\text { Learning }\end{array}$ \\
\hline $\begin{array}{l}\text { Memory: } \\
\text { Short term memory } \\
\text { (verbal) } \\
\text { Long term memory } \\
\text { (visual) } \\
\text { Auditory verbal } \\
\text { memory }\end{array}$ & $\begin{array}{l}\text { Digit span } \\
\text { Benton } \\
\text { Paired words }\end{array}$ & $\begin{array}{l}\text { Abstraction } \\
\text { Concentration } \\
\text { Learning }\end{array}$ \\
\hline
\end{tabular}


Brainstem auditory evoked potentials (BAEPs)These were elicited by mononeural alternative clicks. Interpeak latency I-V and ratio of amplitudes for waves I and $\mathrm{V}$ were analysed.

\section{Cerebral blood flow}

Conventional stationary probe study-Cerebral blood flow in grey matter was determined by the 133xenon technique. ${ }^{25}$ For practical reasons the intravenous route was preferred to inhalation. We analysed the cerebral blood flow in the grey matter of the hemispheres and the presence or absence of increased blood flow in the frontal region (hyperfrontality), present if the ratio frontal cerebral blood flow: mean hemispheric cerebral blood flow was higher than 1 left or right. From 1984 to 198626 persons underwent this examination.

Tomographic cerebral blood flow study-From 1986, cerebral blood flow was measured using 133-xenon single photon emission computed tomography, ${ }^{26} 27$ which does not differentiate grey and white matter. This tomographic method allows study of deep and undertentorial structures (figure). The ratio regional value: hemispheric value was determined.

\section{STATISTICAL PROCEDURES}

Statistical analysis was carried out using the NCSS program, ${ }^{28}$ with parametric or non-parametric tests as appropriate.

For the neuropsychological tests, we studied the percentage of loss of performance referring to the vocabulary test, presumed not to be affected in the case of solvent induced loss of intellectual efficiency: we therefore calculated the ratio: ((SN/MN for vocabulary) - (SN/MN for test studied) $) /(\mathrm{SN} / \mathrm{MN}$ for vocabulary) where $\mathrm{SN}$ is standard note and $\mathrm{MN}$ maximal note for the test.

For cerebral blood flow and evoked potentials, cases and controls were compared and relation to degree of exposure (duration and intensity) was looked for, taking age into account if it was related to the parameter. For parameters that either differed between cases and controls or were related to exposure, the sensitivity and the specificity were assessed considering the neuropsychological tests as the reference examination; this was abnormal if there was a significant difference between the standard notes of the vocabulary test and the other WAIS tests (significant level was given by the fourth version book $^{21}$ ); for paired words, the same method was adopted. For the Benton test the result was considered abnormal if it differed by more than three points from the presumed note. The parameters of evoked potentials and cerebral blood flow were considered abnormal if they exceeded the mean $\pm 1.96 \mathrm{SD}$ of the values found in the control group. The Youden index (sensitivity + specificity -1) was calculated: if it is 0 it indicates that the parameter has no interest; if it is 1 , the parameter has a perfect diagnostic value. ${ }^{29} \mathrm{We}$ also calculated the probability of more abnormal parameters in
Slice 1

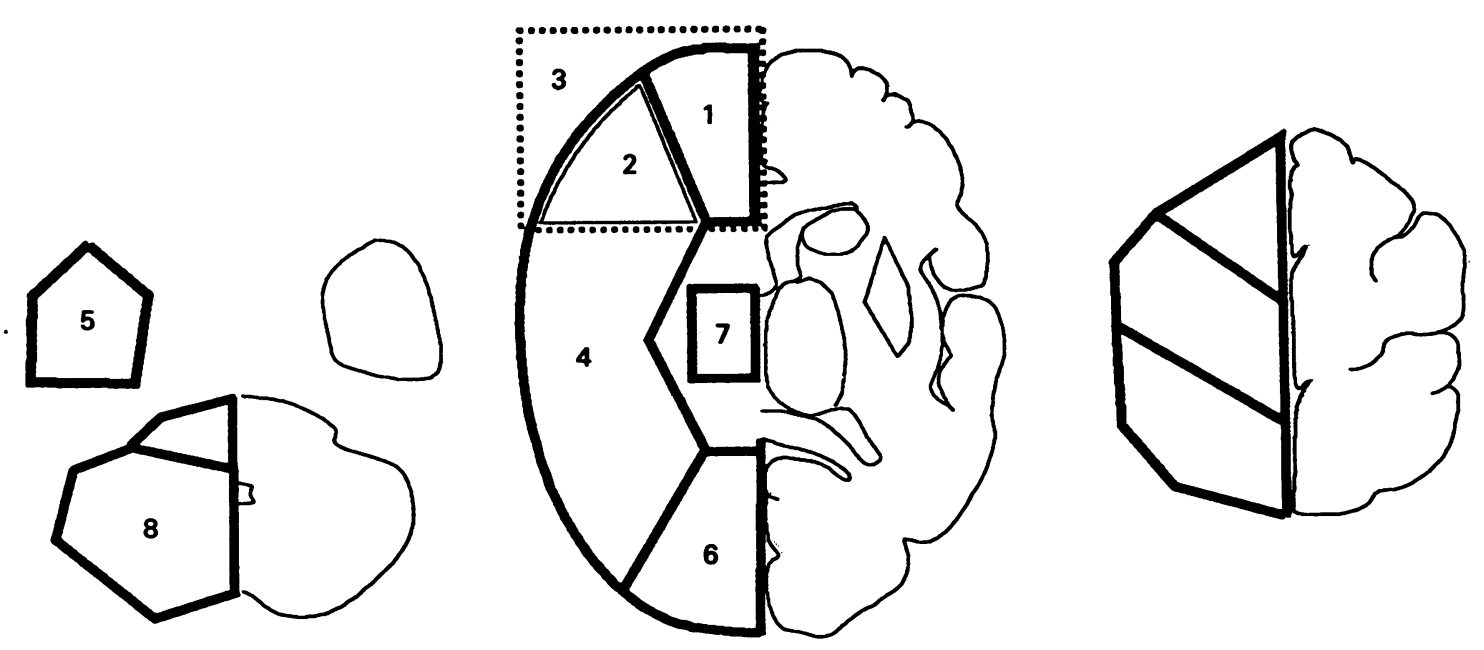

Slice 2

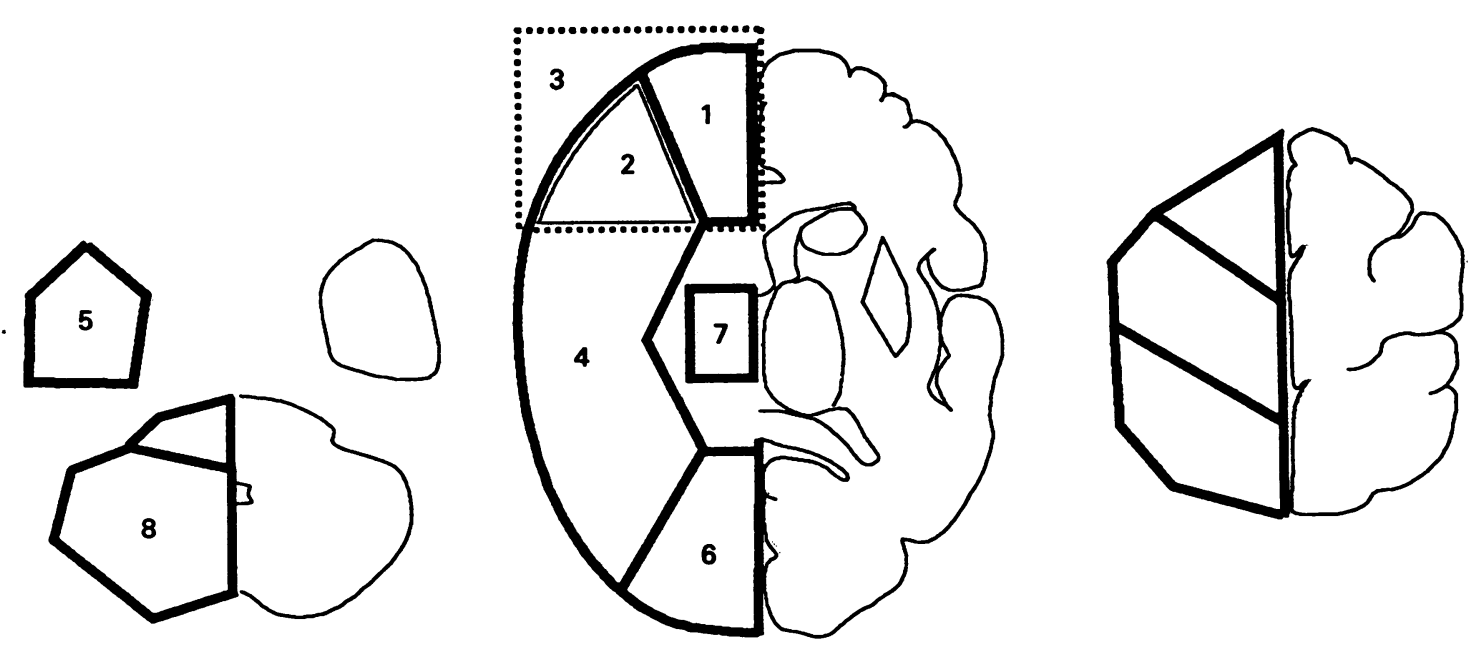

Slice 3

Figure Tomographic study of regional cerebral blood flow. Regions of interest for which were calculated regional values of cerebral blood flow are shown on the left side of each diagram. 1 frontal internal region; 2 middle frontal region:

3 frontal region $=1+2 ; 4$ vascular region of the middle cerebral artery; 5 temporal region; 6 occipital region; 7 thalamus area; 8 cerebellar lobe. 
persons with abnormal psychometric test results than in persons with normal ones.

\section{Results}

COMPARISON OF CASES AND CONTROLS

The P22 and N35 latencies of upper limb SEPs were longer in cases than in controls $(p<0.005)$. Peak to peak amplitude N20-P22 was also longer in cases $(p<0.05)$. Parameters studied for BAEPs and VEPs did not differ significantly between cases and controls (table 3 ).

Cerebral blood flow in grey matter was not significantly different between cases and controls (an analysis of covariance was performed because cases were older than controls and cerebral blood flow decreases with increasing age ${ }^{30}$ ). The lack of physiological hyperfrontal distribution was not more frequent in cases than in controls.

Cerebral blood flow measured by tomography did not differ between cases and controls. For the distribution of regional cerebral blood flow, only the left occipital region was proportionally more perfused in cases than in controls (104 (SD 5.8)\% and $100($ SD 5.5)\% of the flow in the hemisphere $(\mathrm{p}<0.05)$.

SEARCH FOR A LINK BETWEEN DEGREE OF EXPOSURE AND EVOKED POTENTIALS AND CEREBRAL BLOOD FLOW

Duration of exposure was linked only to interpeak latency I-V of BAEPs $(r=0.41, \mathrm{p}<0.05)$. Neither cerebral blood flow (of grey matter or from the tomographic study) nor psychometric tests (expressed in percentage of loss in regard to vocabulary test) were correlated with duration.

For intensity of exposure, the most exposed patients had a higher amplitude N20-P22 of upper limb SEPs $(3.65 \mu \mathrm{v}$ (range $0.15-11.3)$ ) than the least exposed $(2 \cdot 15 \mu v(0 \cdot 3-5 \cdot 0)(p<0 \cdot 01))$. The frontal internal left region was proportionally less perfused in the most exposed (respectively 99 (SD
$7 \cdot 5) \%$ and 105 (SD 7.3)\% of the tomographic (cerebral blood flow, $\mathrm{p}<0.05$ ). The other parameters of evoked potentials, of cerebral blood flow (from the conventional study or from the tomographic study), and psychometric tests did not differ whether intensity of exposure was high or low.

\section{SENSITIVITY AND SPECIFICITY OF EVOKED}

POTENTIALS AND CEREBRAL BLOOD FLOW

We studied parameters that either differed between cases and controls or were linked to degree of exposure.

We established three classifications of normal and abnormal subjects for psychometric tests according to the number of abnormal testsnamely, at least one, at least two, or at least three (respectively 17, 11, and four of the 37 people who underwent the tests).

The number of subjects with abnormal evoked potentials and cerebral blood flow in those classified as abnormal for psychometric tests and those classified as normal was not significantly different.

Specificity of these parameters varied between 0.70 and 1 but sensitivity was always low (less than $0 \cdot 15)$. The Youden index was always less than $0 \cdot 25$ (table 4).

\section{Discussion}

One of the main problems of units of occupational medicine is to find tools that allow the detection, in individual subjects, of abnormalities that have been shown to be present in groups of workers exposed to a given substance. After epidemiological studies and experimental research that assess the existence of a phenomenon, we have to look for the criteria that allow us to assert that a person is ill or not. This study showed that the group of 50 patients differed from controls in several parameters of evoked potentials and cerebral blood flow. The individual diagnostic interest of these examinations

Table 3 Evoked potentials in cases and in controls

\begin{tabular}{|c|c|c|c|}
\hline & $\begin{array}{l}\text { Cases }(n=50) \\
\text { Mean (range) }\end{array}$ & $\begin{array}{l}\text { Controls }(n=40) \\
\text { Mean (range) }\end{array}$ & p Value \\
\hline $\begin{array}{l}\text { Somatosensory evoked potentials } \\
\text { N20 latency (ms) } \\
\text { P22 latency (ms) } \\
\text { N35 latency (ms) } \\
\text { N20-P22 amplitude ( } \mu \mathrm{V})\end{array}$ & $\begin{array}{l}19 \cdot 9(17 \cdot 7-21 \cdot 6) \\
24 \cdot 4(21 \cdot 2-29 \cdot 5) \\
33 \cdot 9(27-40) \\
3 \cdot 10(0 \cdot 15-11 \cdot 3)\end{array}$ & $\begin{array}{r}19 \cdot 7(18 \cdot 2-21 \cdot 1) \\
23 \cdot 1(21 \cdot 2-27 \cdot 9) \\
32 \cdot 0(27 \cdot 3-39 \cdot 2) \\
2 \cdot 06(0 \cdot 43-8 \cdot 7)\end{array}$ & $\begin{array}{l}\text { NS } \\
<0.005 \\
<0.005 \\
<0.05\end{array}$ \\
\hline $\begin{array}{l}\text { Brainstem auditory evoked poten } \\
\text { Interpeak latency of I-V (ms) } \\
\text { Ratio of amplitudes: A1/A5 }\end{array}$ & $\begin{array}{l}4 \cdot 08(3 \cdot 64-4 \cdot 68) \\
0.69(0 \cdot 18-1 \cdot 22)\end{array}$ & $\begin{array}{l}4.06(3 \cdot 6-4 \cdot 52) \\
0 \cdot 58(0 \cdot 17-1 \cdot 28)\end{array}$ & $\begin{array}{l}\text { NS } \\
\text { NS }\end{array}$ \\
\hline $\begin{array}{l}\text { Visual evoked potentials: } \\
\text { P100 latency (ms) } \\
\text { P100-N140 amplitude }(\mu \mathrm{V}) \\
\text { Wave w present } \\
\text { Wave w absent }\end{array}$ & $\begin{array}{l}107 \cdot 2(88-123) \\
4 \cdot 57(2 \cdot 9-16) \\
38 \\
11\end{array}$ & $\begin{array}{l}107 \cdot 2(99-117) \\
4 \cdot 85(1-11 \cdot 3) \\
33 \\
6\end{array}$ & $\begin{array}{l}\text { NS } \\
\text { NS } \\
\text { NS }\end{array}$ \\
\hline
\end{tabular}


Table 4 Youden index for parameters of evoked potentials and cerebral blood flow that either differed between cases and controls or were linked to degree of exposure

\begin{tabular}{lllllll}
\hline & $\begin{array}{l}S E P \\
P 22 \text { latency }\end{array}$ & $\begin{array}{l}S E P \\
\text { N35 latency }\end{array}$ & $\begin{array}{l}S E P \\
\text { N20-P22 amplitude }\end{array}$ & $\begin{array}{c}\text { BAEP } \\
\text { latency I-V }\end{array}$ & $\begin{array}{l}C B F \\
\text { Frontal internal left }\end{array}$ & $\begin{array}{l}C B F \\
\text { Occipital left }\end{array}$ \\
\hline $\begin{array}{l}\text { Normality cut off: } \\
\quad \text { abnormal psychometric test }\end{array}$ & 0.18 & 0.06 & 0.13 & 0.15 & 0 & 0.22 \\
$\begin{array}{c}\text { Normality cut off: } \\
\quad \text { 2 psychometric tests abnormal }\end{array}$ & 0.17 & 0.04 & 0.08 & 0.12 & 0 & 0.18 \\
$\begin{array}{l}\text { Normality cut off: } \\
\quad 3 \text { psychometric tests abnormal }\end{array}$ & 0.24 & 0.04 & 0.06 & 0.09 & 0 & 0.13 \\
\hline
\end{tabular}

SEP = Somatosensory evoked potential; $\mathrm{BAEP}=$ brainstem auditory evoked potential; $\mathrm{CBF}=$ cerebral blood flow.

was evaluated by calculation of specificity and sensitivity of these parameters, with psychometric tests as reference: these examinations had a good specificity but a very low sensitivity.

The first part of our study investigated the group of 50 consulting patients. By contrast with epidemiological studies, the group was not homogeneous; this probably explains why we did not find any relation between psychometric tests and degree of exposure. Duration of exposure was variable, ranging from one year to 37 years. We included patients with at least one year of exposure although the hypothesis has been made that symptoms of solvent induced psycho-organic syndrome appear only after several years of exposure. ${ }^{31}$

In the second part of the study, we looked for the diagnostic value of evoked potentials and cerebral blood flow. Examinations other than psychometric tests would be useful for the diagnosis of solvent induced psycho-organic syndrome. Indeed, socioeconomic background and linguistic difficulties do not always allow the correct execution of psychometric tests, which is why we had to exclude some patients from this part of the study. Moreover, there is no consensus about the type and the number of abnormal psychometric tests necessary to distinguish normal from abnormal patients. We made three classifications to declare subjects as abnormal: the cut off was either one, two, or three abnormal psychometric tests (independent of the function tested); results were not noticeably different: we were unable to show a diagnostic value for any of the parameters that either differed between cases and controls, or were linked to degree of exposure.

Results of other studies conducted on evoked potentials in populations exposed to solvents (other than n-hexane) are contradictory-namely, no abnormality of VEPs ${ }^{32}$ or BAEPs, ${ }^{33} 34$ increased latencies ${ }^{33} 35$ and modified amplitudes of VEPs (decreased $^{35}$ or increased ${ }^{31}$ ), and increased latencies of BAEPs indicating a lesion of white matter (this examination is more sensitive than cerebral magnetic resonance imaging). ${ }^{20}$ But the populations of these studies were different: two were exposed for a short time during experimental studies $^{32}{ }^{33}$; three, from cross sectional epidemiological studies, were exposed for a long time and probably to similar solvents and atmospheric concentrations 3134 35; and one intensively, for a long time (sniffers with high exposure). ${ }^{20}$ This probably explains discrepancies among the results.

Our study does not confirm the decrease in cerebral blood flow of grey matter found by others. ${ }^{36-39}$ This may be the effect of a less evolved disease, ${ }^{36} 3739$ of a lower exposure, ${ }^{38}$ of an insufficient number of patients, or of the heterogeneity of our population.

Cerebral blood flow measured by tomography was also not decreased at a group level, and regional analysis showed only an increase of left occipital distribution in cases compared with controls. This is difficult to interpret, as is the negative relation between the left frontal internal distribution and the intensity of exposure. These positive unilateral results may have occurred by chance and at an individual level, are not of diagnostic interest.

Requests for reprints to: Dr S Dally, Hôpital Fernand Widal, 200 rue du Faubourg Saint-Denis, 75475 Paris Cedex 10 France.

1 Anger WK. Worksite behavioral research. Results, sensitive methods, test batteries and the transition from laboratory data to human health. Neurotoxicology 1990;11:627-717.

2 World Health Organisation. Report on a Joint world health organisation/Nordic Council of Ministers Working Group Copenhagen, 1981. Chronic effects of organic solvents on the central nervous system and diagnostic criteria Copenhagen: WHO, 1985 (report No 5).

3 Edling C, Ekberg K, Ahlborg G, et al. Long term follow up of workers exposed to solvents. Br F Ind Med 1990;47:75-82.

4 Sokoloff $L$. Relationship among local functional activity, energy metabolism and blood flow in the central nervous system. Federation Proceedings 1981;40:2311-6.

5 Berglund M. Cerebral blood flow in chronic alcoholics. Alcohol Clin Exp Res 1981;5:295-303.

6 Diamond I. Studies of acute and chronic effects of ethanol on early evoked potentials. Alcohol 1987;4:255-6.

7 Mortimer MJ, Good PA, Marsters JB, Addy DP. Visual evoked responses in children with migraine: a diagnostic test. Lancet 1990;i:75-7.

8 Lou HS, Henriksen L, Bruhn P. Focal cerebral dysfunction in developmental learning disabilities. Lancet 1990;i:8-11.

9 Lille F, Hazemann P, El Massioui F, Lesèvre N, Dally S. Effect of chronic alcohol intake and short-term abstinence on early sensory EPs and late "cognitive" ERPs. Current trends in event related potential research 1987;supp 40:712-8.

10 Borstein RA, Miller HB, Van Schoor T. Neuropsychological 
deficit and emotional disturbance in head-injured patients. $\mathcal{F}$ Neurosurg 1989;70:509-13.

11 Homan RW, Paulman RG, Devous MD, Walker P, Jennings LW, Bonte FJ. Cognitive function and regional cerebral blood flow in partial seizures. Arch Neurol 1989;49:964-70.

12 Weinstein GW, Odom JV, Cavender S. Visually evoked potentials and electroretinography in neurologic evaluation. Neurol Clin 1991;9:225-42.

13 Myers RAM, Britten JS. Are arterial blood gases of value in treatment decisions for carbon monoxide poisoning? Crit Care Med 1989;17:139-42.

14 Stollery BT, Banks HA, Broadbent DE, Lee WR. Cognitive functioning in lead workers. $B r F$ Ind Med 1989;46:698-707.

15 Soleo L, Urbano ML, Petrera V, Ambrosi L. Effects of low exposure to inorganic mercury on psychological performance. Br F Ind Med 1990;47:105-9.

16 Herskowitz A, Ishii N, Schaumburg H. n-Hexane neuropathy. A syndrome occurring as a result of industrial exposure. $N$ Engl F Med 1971;285:82-5.

17 Seppäläinen AM, Raitta C, Huuskonen MS. n-Hexaneinduced changes in visual evoked potentials and electroretinograms of industrial workers. Electroencephalogr Clin Neurophysiol 1979;47:492-8.

18 Mutti A, Ferri F, Lommi G, Lotta S, Lucertini S, Franchini I. $n$ Hexane-induced changes in nerve conduction velocities and somatosensory evoked potentials. Int Arch Occup Environ Health 1982;51:45-54.

19 Chang YC. Neurotoxic effects of $n$-hexane on the human central nervous system: evoked potential abnormalities in n-hexane polyneuropathy. $\mathcal{f}$ Neurol Neurosurg Psychiatry 1987;50:269-74.

20 Rosenberg NL, Spitz MC, Filley CM, Davis KA, Schaumburg $\mathrm{HH}$. Central nervous system effects of chronic toluene abuse. Clinical, brainstem evoked response and magnetic resonance imaging studies. Neurotoxicol Teratol 1988;10:489-95.

21 Wechsler D. Wechsler adult intelligence scale-revised manual. New York: Psychological Corporation, 1981.

22 Benton AL. The revised visual retention test. New York: Psychological Corporation, 1974.

23 Manuel de l'échelle clinique de mémoire de D Wechsler. Paris: Centre de psychologie appliquée, 1969.

24 Mattarazzo JD. Wechsler's measurement and appraisal of adul intelligence. 5th ed. Baltimore: Williams and Wilkins, 1972.

25 Meric P, Seylaz J, Correze JL, Luft A, Mamo H Measurement of regional blood flow by intravenous injections of ${ }^{133}$ Xenon. Acta Neurol Scand 1977;56(supp 64): 462-3.

26 Stokely EM, Sveindottir E, Lassen NA, Rommer PA. Single photon dynamic computer-assisted tomograph (D CAT) for imaging brain function in multiple cross sections. $\mathcal{f}$ Comput Assist Tomogr 1980;4:230-40.

27 Celsis P, Goldman T, Henriksen L, Lassen NA. A method for calculating regional blood flow from emission computed tomography of inert gas concentrations. $\mathcal{f}$ Comput Assist Tomogr 1981;5:641-5.

28 Number Cruncher Statistical System (5th ed), Kaysrille, Hintze $\mathrm{JL}, 1987$.

29 Youden WJ. Index for rating diagnostic tests. Cancer 1950;3:32-5.

30 Lavy S, Melamed E, Cooper G, Bentin S, Rinot Y. Regional cerebral blood flow in patients with Parkinson's disease. Arch Neurol 1979;36:344-8.

31 Elofsson S, Gamberale F, Hindmarsh T, et al. Exposure to organic solvents: a cross-sectional epidemiologic investigation on occupationally exposed car and industrial spray painters with special reference to the nervous system. Scand $\mathcal{f}$ Work Environ Health 1980;6:239-73.

32 Seppäläinen AM, Savolainen K, Kovala T. Changes induced by xylene and alcohol in human evoked potentials. Electroencephalogr Clin Neurophysiol 1981;51:148-55.

33 Altmann L, Bottger A, Wiegand H. Neurophysiological and psychophysical measurements reveal effects of acute lowlevel organic solvent exposure in humans. Int Arch Occup Environ Health 1990;62:493-9.

34 Antti-Poika M, Ojala M, Matikainen E, Vaheri E, Juntunen J. Occupational exposure to solvents and cerebellar, brainstem and vestibular functions. Int Arch Occup Environ Health, 1989;61:397-401.

35 Urban P, Lukas E. Visual evoked potentials in rotogravure printers exposed to toluene, $B r f$ Ind Med 1990;47:819-23.

36 Arlien-Soborg P, Henriksen L, Gade A, Gyldensted C, Paulson OB. Cerebral blood flow in chronic toxic encephalopathy in house painters exposed to organic solvents. Acta Neurol Scand 1982;66:34-41.

37 Maximilian VA, Risberg J, Prohovnik I, Rehnström S, HaegerAronsen B. Regional cerebral blood flow and verbal memory after chronic exposure to organic solvents. Brain Cogn 1982;1:196-205.

38 Risberg J, Hagstadius S. Effects on the regional cerebral blood flow of long-term exposure to organic solvents. Acta Psychiatr Scand 1983;67:92-9.

39 Hagstadius S, Orbaek P, Risberg J, Lindgren M. Regional cerebral blood flow at the time of diagnosis of chronic toxic encephalopathy induced by organic-solvent exposure and after the cessation of exposure. Scand $\mathcal{f}$ Work Environ Health 1989;15:130-5.

Accepted 6 July 1992 